\title{
OS ESPAÇOS E MATERIAIS COMO ELEMENTOS FAVORECEDORES DA CONSTRUÇÃO DO CONHECIMENTO LÓGICO-MATEMÁTICO NA EDUCAÇÃO INFANTIL
}

\author{
Mateus Lorenzon ${ }^{1}$ \\ Jacqueline Silva da Silva ${ }^{2}$
}

\begin{abstract}
Resumo: Neste estudo, analisa-se de que forma os espaços e materiais favorecem a construçáo do conhecimento lógico-matemático em crianças de três anos. Os pressupostos teóricos que sustentam o estudo são decorrentes de uma perspectiva construtivista, sendo que propóe-se uma interface com autores que abordam a concepçáo dos espaços e materiais como um segundo educador. A investigação caracteriza-se como uma pesquisa-ação e foi desenvolvida enquanto docente de uma turma de Maternal de uma Escola Municipal de Educaçáo Infantil, localizada em Lajeado/RS. Para a produção do corpus da pesquisa utilizou-se de Diários de Campo, Filmagens e Fotografia, sendo estes analisados por meio de uma abordagem reflexiva e dispostos em duas categorias. A primeira categoria produzida trata das contribuiçóes do espaço para o desenvolvimento da aprendizagem. Por sua vez, a segunda categoria aborda a importância dos materiais para o brincar simbólico presentes no espaço para o desenvolvimento do conhecimento lógico-matemático.
\end{abstract}

Palavra-chave: Educação Infantil. Espaços e Materiais. Conhecimento Lógico-Matemático.

\section{SPACES AND MATERIALS AS FAVORING ELEMENTS OF THE CONSTRUCTION OF LOGICAL-MATHEMATICAL KNOWLEDGE IN EARLY CHILDHOOD EDUCATION}

\begin{abstract}
In this study, it is analyzed how the spaces and materials favor the construction of the logical-mathematical knowledge in children of 3 years. The theoretical assumptions that support the study are derived from a constructivist perspective, and it is proposed an interface with authors that approach the conception of spaces and materials as a second educator. The study is characterized as an action research and was developed as a teacher of a Maternal class from a Municipal School
\end{abstract}

1 Graduado do Curso de Pedagogia. Discente do Programa de Pós Graduação em Ensino. Centro Universitário UNIVATES.

2 Doutora em Educação - UFRGS. Professora do Programa de Pós Graduação em Ensino UNIVATES. 
of Early Childhood Education, located in Lajeado / RS. For the production of the corpus of the research used of Field Diaries, Filming and Photography, being these analyzed by means of a reflexive approach and arranged in two categories. The first category produced deals with the contributions of space to the development of learning. In turn, the second category addresses the importance of the symbolic playing materials present in space for the development of logical-mathematical knowledge.

Keywords: Child education. Spaces and Materials. Logical-Mathematical Knowledge.

\section{INTRODUÇÂO}

Neste artigo - decorrente de uma pesquisa-ação, desenvolvida enquanto docente de uma turma de Maternal de uma Escola Municipal de Educação Infantil, localizada em Lajeado/RS - analisa-se de que forma os espaços e materiais favorecem a construção do conhecimento lógico-matemático em crianças de 3 anos. Para o estudo, aproxima-se as teorias de Piaget (1977) e Kamii (2012), sobre os processos de construção do conhecimento lógico-matemático, com autores que abordam a temática da organização do espaço como um segundo educador (FORNEIRO, 1999; HORN, 2004; GANDINI, 2016).

Em uma perspectiva construtivista, parte-se do pressuposto que a criança age ativamente no processo de construção de estruturas mentais, isto é, esquemas pelos quais os indivíduos organizam intelectualmente o meio. Ao pensar-se acerca dos processos de construção do conhecimento matemático, evidenciase assim que as primeiras operações com números e identificação das diferentes propriedades lógico-matemáticas não é decorrente de uma apreensão mecânica, mas sim do estabelecimento de contínuas relações. Kamii (2012) defende assim, que, diferentemente do conhecimento social ou físico, "a fonte do conhecimento lógico-matemático [...] é interno".

Para compreender o processo de desenvolvimento lógico-matemático, tornase necessário retomar os três conceitos centrais do pensamento de Piaget (1977): a assimilação, a acomodação e a equilibração. Para o autor, todo indivíduo comporta uma estrutura cognitiva e, por uma propensão inata, busca o reequilíbrio caso essa estrutura sofrer algum desequilíbrio. Pode-se entender que a estrutura cognitiva compreende a um conjunto de conhecimento sistematicamente organizados pelo indivíduo e que possibilitam a ele uma leitura e compreensão do mundo. As novas aprendizagens ou informações retidas podem ser assimiladas - quando articuladas ao esquema cognitivo sem desequilibrá-lo - ou provocar uma acomodação. Nesse último caso, as informações provocam um desequilíbrio e, consequente, reorganização de todo o esquema existente.

Uma das fases mais reconhecidas e aplicadas do construtivismo refere-se ao uso de materiais concretos. Kamii (2012) entende que o uso desses objetos nos processos de ensino, possibilita que as crianças a construção de relações metais entre os diferentes objetos. É por meio do estabelecimento e complexificação das relações estabelecidas entre os materiais que a criança começa a construir o seu conhecimento lógico-matemático. Frente a isso, torna-se essencial pensar os espaços e recursos pedagógicos como elementos que garantam a ação autônoma 
das crianças e as instiguem a estabelecer inúmeras relações entre os diferentes objetos.

Entende-se que o espaço precisa ser pensado como um princípio de trabalho. Para autores, entre os quais Fortunatti (2014, p. 43), o contexto físico "é considerado como fundamental para as experiências das crianças, como algo que sustenta e alimenta o processo de aprendizagem, em vez de representar o simples cenário". Nesse viés, o espaço é um segundo educador que age como um elemento que instiga as descobertas das crianças e oportuniza experiências que provocam a reorganização de suas estruturas cognitivas.

Diante do exposto, salienta-se que o objetivo deste estudo consiste em analisar de que modo a organização dos espaços e materiais favorece a construção do conhecimento lógico-matemático de crianças de 3 anos que frequentam uma Escola Municipal de Educação Infantil localizada em Lajeado/RS. O artigo está organizado em duas seções, sendo que na primeira, intitulada "Procedimentos Metodológicos", apresenta-se os instrumentos empregados para a produção do corpus da pesquisa e a abordagem utilizada para realização da análise do corpus. Posteriormente, na seção intitulada "Os Espaços e Materiais como favorecedores da construção do conhecimento matemático", descreve-se e analisa-se as situações vivenciadas.

\section{PROCEDIMENTOS METODOLÓGICOS}

Esse estudo é decorrente de uma pesquisa-ação desenvolvida junto a uma turma de Maternal de uma Escola Municipal de Educação Infantil localizada em Lajeado/RS. Para a realização da investigação, optou-se pelo desenvolvimento de uma pesquisa-ação, que configura-se como "um método usado (...) normalmente por professores para registrar suas próprias observações com exatidão, enquanto revelam os significados que os seus sujeitos trazem para suas experiências de vida" (GANDINI, 2012, p. 218). Assim, essa abordagem de pesquisa, na perspectiva apresentada, implica na transformação de uma temática que desperta o interesse dos docentes em um tema de estudo.

Para Rinaldi (2016), a pesquisa-ação é compreendida como uma ação ético-existencial necessária em um contexto de profundas mudanças culturais. A investigação, associada a própria ação do sujeito, favorece o desenvolvimento de um empreendimento de buscar e evidenciar os valores e pressupostos teóricos que norteiam as práticas docentes, favorecendo o desenvolvimento de um contínuo processo de desenvolvimento profissional. Uma vez que fala-se em uma pesquisa indissociada da docência, destaca-se que este estudo foi desenvolvido enquanto docente da turma investigada.

Nessa perspectiva, no início do ano letivo delimitou-se um projeto de investigação-ação que buscava evidenciar as contribuições das intervenções no espaço para o desenvolvimento dos saberes lógico-matemáticos das crianças. O uso da pesquisa-ação como um princípio de trabalho oportuniza que "o conhecimento 
entre no circuito da ação de modo permanente e a modifica em caráter contínuo, ao mesmo tempo em que sofre modificações" (RINALDI, 2016, p. 181).

Os dados apresentados no decorrer do estudo foram obtidos por meio do uso de Diário de Aula, no qual o docente realiza uma análise das práticas pedagógicas que realiza com as crianças e registra episódios que acompanha diariamente. Além disso, foram utilizados registros fotográficos e filmagens de situações, sendo que estas foram transcritas para a análise. Esse acompanhamento sistemático das atividades, evidenciou o modo pelo qual as crianças desenvolvem o próprio pensamento e de que modo os espaços e materiais as influenciam na construção do seu conhecimento.

A análise dos dados foi realizada mediante o emprego de uma abordagem reflexiva que, conforme Alarcão (2008), não restringe-se a mera descrição ou narrativa de determinados acontecimentos, mas envolve a interpretação dos fenômenos acompanhados e resulta na produção de um saber da ação pedagógica. A fim de garantir o caráter ético do estudo, não será identificada o nome da instituição participante do estudo e nem das crianças envolvidas. Com o objetivo de identificar as crianças, empregou-se um sistema de código, pelo qual cada indivíduo foi nomeado por Criança 1, Criança 2, Criança 3, e assim sucessivamente, até Criança 17.

\section{OS ESPAÇOS E MATERIAIS COMO FAVORECEDORES DA CONSTRUÇÁO DO CONHECIMENTO MATEMÁTICO}

Nesta seção do estudo apresenta-se a análise do corpus da pesquisa. Os episódios foram agrupados em duas categorias distintas. Na primeira, discutese acerca dos modos pelos quais o espaço contribui para o desenvolvimento das aprendizagens lógico-matemáticas das crianças. Por sua vez, na segunda categoria, disserta-se sobre a importância dos materiais para o brincar simbólico e a posterior compreensão do conhecimento lógico-matemático.

Para a primeira categoria, parte-se do pressuposto que o espaço consiste um segundo educador que favorece ou inibe as relações das crianças com os seus pares e com os materiais presentes. Nesse viés, Horn (2004) entende que a arquitetura das escolas e a disposição dos materiais precisa ser planejada com intencionalidade, visto que sua organização oportunizaria novas experiências sensoriais, sinestésicas e cognitivas. Assim, o espaço, além de ser um cenário no qual as relações interpessoais das crianças ocorrem, precisa ser pensado como um suporte para suas experimentações. Para o desenvolvimento das práticas pedagógicas, partiu-se do pressuposto que inserções intencionais de recursos no espaço físico da sala de aula fazem com que estes locais transformem-se em ambientes de aprendizagem.

Assim, na primeira categoria agrupou-se diferentes episódios que retratavam como as interações das crianças e dos espaços, oportunizam a construção do conhecimento lógico-matemático. Dentre estes episódios destaca-se o interesse das crianças por formas geométricas, o que levou os docentes a decorarem o chão da 
sala com figuras geométricas planas. No Diário de Aula do docente encontramos o seguinte excerto:

No mês de maio de 2016, tornava-se latente o interesse das crianças nas figuras geométricas. A curiosidade por esse tema, foi despertada porque nos momentos de musicalização, cantávamos a canção "O Meu chapéu tem três pontas". A partir dessa atividade, as crianças, espontaneamente, começaram a procurar objetos que tinham três pontas para mostrar ao professor. Frente a isso, decorou-se o chão da sala de aula com figuras geométricas planas (quadrado, circulo, retângulo e triângulo) em dois tamanhos (grande e pequeno) (Diário de Aula, Avaliação Mensal - Maio de 2016).

Nos momentos livres, tornava-se visível que as crianças se debruçavam sobre figuras geométricas identificando as diferenças e semelhanças existente entre elas, sendo que em algumas ocasiões elas manipulavam os objetos presentes no espaço e os colocavam sobre as figuras fixadas no chão, com o intuito de comparar as dimensões e outras propriedades físicas:

$\mathrm{Na}$ sala de aula há um tapete de EVA com encaixes em formas geométricas que as crianças costumam utilizar nos momentos livres. No final da tarde, um grupo de crianças brinca de encaixar as peças, quando a Criança 17 dirige-se ao tapete e recolhe figuras de EVA. Ela circula pela sala observando as figuras que estão no chão. Ela coloca um objeto de formato quadrangular de EVA laranja sobre um quadrado fixado no chão, chama os colegas e afirma "Eles são parecidos, mas não iguais. Olhem, as cores são diferentes" (Diário de Aula, Registro de 31 de maio de 2015).

Ao retomar os registros individuais das crianças, percebe-se que a Criança 17, desde o início das atividades, demonstrou um maior envolvimento com as situações que envolvessem a geometria. Em ocasiões de brincar livre, ela buscava uma caixa de Blocos Lógicos ${ }^{3}$ existente na sala para que pudesse usar nas comparações que estabelecia. Destaca-se que nessas atividades, a Criança 17 passou a usar com mais frequência as expressões figuras parecidas e figuras diferentes.

Por meio da análise das situações descritas, percebe-se que por meio das situações vivenciadas, a criança aprimorou suas habilidades matemáticas ou as exercitou, compartilhando com os colegas o conhecimento produzido. Nas situações analisadas, a Criança 17 colocou os objetos em uma relação própria. Ao comparar o objeto com a face em forma de um triângulo amarelo que estava em sua mão, com o triângulo azul fixado no chão (de igual tamanho e forma), optou por afirmar que ambos eram parecidos, empregando a propriedade da cor para identificar a diferença entre eles. Por meio dessas interações das crianças com seus pares e com os espaços/materiais, as crianças passaram a nomear as formas a partir de suas diferentes características. Assim, além das identificações usuais de cores

3 O Jogo de Blocos Lógicos contém 48 peças que são divididas em três cores (azul, amarelo e vermelho), quatro formas (círculo, retângulo, triângulo e quadrado), dois tamanhos (grande e pequeno) e duas espessuras (grosso e fino). 
e formatos, as crianças passaram identificar formas bebês (figuras geométricas pequenas) e formas papais e mamães (formas maiores)

Nos exemplos citados acima, percebe-se que as crianças começaram a desenvolver o conhecimento lógico-matemático. Piaget (1977), em seus estudos de epistemologia, distingue três tipos de conhecimento: o conhecimento social, conhecimento físico e conhecimento lógico-material. O conhecimento físico, segundo Kamii (2012, p. 17) "é o conhecimento dos objetos da realidade externa [...] e podem ser conhecidos pela observação". Assim, ele é inerente ao objeto e pode ser exemplificado com a propriedade de peso e cor que estão no objeto. Em contrapartida, a diferença entre as propriedades de diferentes objetos corresponde a uma construção individual. Por exemplo, duas plaquetas são iguais em peso e tamanho, mas cores diferentes. Esta diferença é um conhecimento lógicomatemático.

A diferença é uma relação criada mentalmente pelo indivíduo que relaciona
os dois objetos. A diferença é relação criada mentalmente pelo indivíduo que
relaciona os dois objetos. A diferença não está nem em uma plaqueta nem em
outra. Se a pessoa não colocasse os objetos dentro desta relação, para ela não
existiria a diferença (KAMII, 2012, p. 17).

Nesse sentido, as relações que as crianças estabeleciam entre as diferentes figuras geométricas, não implicavam somente reconhecer que elas eram diferentes, mas em conformidade com Kamii (2012), requerem o estabelecimento de uma relação mental por parte do indivíduo. Assim, as diferentes figuras geométricas foram postas em relação pelas crianças, que passaram a identificar as diferentes propriedades de um mesmo objeto.

Percebe-se a importância da organização do espaço como um elemento facilitador das aprendizagens infantis e que estimula as crianças a estabelecerem relações entre os múltiplos objetos ali existentes. Para que isso ocorra, torna-se necessário pensar em um espaço flexível, adequado aos interesses e necessidades das crianças. Gandini (2016, p. 335) destaca que "ele [o espaço] precisa passar por modificações frequentes de parte das crianças e dos professores para se manter atualizado e responsivo às suas necessidades de serem protagonistas na construção do próprio conhecimento". Assim, cabe aos docentes desenvolver um processo de escuta constante, a fim de identificas as mudanças necessárias com o intuito de transformá-lo em um recurso que é suporte de oportunidades para às crianças:

É importante garantir às crianças respostas às suas necessidades, compatíveis com os níveis e autonomia observados e as habilidades e competências possuídas, de modo a não colocar muita frustração, mas também incentivando a ativação de padrões de pensamento e ação que se colocam no nível proximal de desenvolvimento (TOGNETTI, 2014, p. 31)

No contexto do estudo, acredita-se que é preciso valorizar todos os espaços existentes no contexto da sala de aula, inclusive o chão, visto que é nesse local que crianças mais pequenas tendem a se exercitar e explorar. Frente a isso, recursos e objetos devem ser selecionados e dispostos nesse local com o intuito de agirem 
como elementos provocadores e que lançam as crianças em um constante exercício da dúvida e em pequenas investigações.

A segunda categoria retrata a importância dos materiais para o brincar simbólico e a posterior compreensão do conhecimento lógico-matemático. Nessa categoria, foram reunidos episódios documentados que retratam situações lúdicas que envolveram as crianças. Entende-se que, quando os sujeitos se envolvem em atividades lúdicas eles conseguem desenvolver e aperfeiçoar suas habilidades físicas e intelectuais (MOYLES, 2002).

Em um primeiro momento, apresenta-se um episódio em que as crianças exploravam o Recanto dos Materiais Não Estruturados. Neste espaço, são disponibilizadas as crianças diferentes objetos, entre os quais destaca-se cones plásticos, peças de madeira, tampas, pedaços de cordinhas, caixas de diferentes dimensões.

No dia 04 de agosto, enquanto o docente de turma e as crianças montam legos no espaço central da sala, a Criança I., dirige-se para o Recanto dos Materiais Não-Estruturados. Nesse espaço, seleciona uma caixa de ovos vazia e um pote com tampas de garrafa PET coloridas e, em seguida, se envolve em uma atividade de colocar em cada um dos espaços da caixa uma tampa azul. Ao perceber que faltariam tampas azuis, ela dirige-se ao professor solicitando novas tampas. Ele a questiona sobre o que está construindo, então ela o chama para ver a atividade que desenvolveu. Outras crianças se aproximam para ver o trabalho desenvolvido pela colega (Diário de Campo, Registro do dia 04 de agosto).

No excerto transcrito acima, torna-se evidente que os materiais presentes possibilitaram a criança o desenvolvimento de um empreendimento que envolve operações de conservação de número. Em outra situação transcrita, a mesma criança "retira suas tampas da caixa e as agrupa em um pequeno monte. Posteriormente, repete a atividade anterior, recolocando as tampas na caixa" (Diário de Campo, 12 de agosto). Para Kamii (2012) as atividades de conservação de número exigem que a criança reconheça que o número de objetos permaneça igual independente do arranjo espacial que os objetos se encontram. Em sequência a esta atividade, uma nova situação é observada:

Observando o interesse dos colegas pela atividade de colocar tampas coloridas nas caixas de ovos, a Criança 1 também dirige-se para o Espaço dos Materiais Não Estruturados e pega para si uma caixa e tampas. Senta-se no chão e coloca duas tampas em cada espaço. Como sobram algumas tampas, coloque três em alguns espaços. Pega sua caixa e aproxima-se do docente: "Você quer um brigadeiro?". O docente finge comer uma das tampinhas, então a criança dirige-se a Criança 13 e repete a ação, ela porém afirma "Não é assim. Aqui algumas tem três tampas e só pode uma". A criança observa sua caixa de tampas e em seguida começa retirar as tampas excedentes.

No excerto transcrito acima, percebe-se que em um primeiro momento a Criança 1 não consegue compreender a regra de funcionamento da atividade, isto é, a associação termo a termo, mas realiza a mesma atividade que os colegas com 
um objetivo simbólico. Mais do que um momento de exploração livre, as situações de brincar no contexto da Educação Infantil devem servir "para identificar as necessidades individuais quanto para proporcionar medidas palitativas" (MOYLES, 2002, p. 144). No caso da situação relatada, é por meio de uma situação que se tornou visível que a criança possuía uma dificuldade referente a compreensão da lógica matemática envolvida na atividade.

Logo após o registro e reflexão dessas situações, o docente expõe no Diário de Aula da turma, que inspirado nas teorizações de Kamii (2012), disponibilizou para as crianças pequenas caixas de ovos com apenas quatro lugares para colocar tampas, para facilitar que elas realizassem operações com números perceptuais. Destaca-se assim, importância de desenvolver um processo de escuta sensível das situações acompanhadas a fim de delimitar situações de aprendizagem que serão desenvolvidas posteriormente. Rinaldi (2016) destaca que o acompanhamento das situações e a reflexão sobre as práticas realidades, possibilita que o professor "pode basear seu ensino naquilo que deseja ensinar, mas naquilo que a criança deseja aprender" (RINALDI, 2016, p. 185).

Entende-se que a dificuldade de as crianças realizarem a associação termo a termo pode estar relacionada com a falta de habilidade para desenvolver operações de identificação e conservação. Uma das críticas contemporâneas ao pensamento construtivista, é que a divisão do desenvolvimento humano em fases definidas pela faixa etária poderia criar um parâmetro rígido e uma norma de desenvolvimento. Um exemplo, é um diálogo gravado entre a Criança 12 e a Criança 7. A Criança 7 estava brincando com ferramentas plásticas e pegou seis parafusos disponíveis para si. A Criança 12 precisava desse material para encaixar duas pequenas placas plásticas, então tenta retirar o brinquedo do colega. Ao observar o conflito, o docente aproxima-se e pede para eles dividirem os brinquedos. A Criança 12 pega cinco parafusos do colega, e o docente pede para devolver um, pois ele tem muito mais que seu colega. A Criança 7 afirma que ele não tem mais que o seu amigo, mas ambos têm a mesma quantidade, pois a Criança 7 ainda tem um. A análise da situação possibilita realizar diferentes análises, entre as quais a necessidade de adequar a linguagem para dialogar com as crianças. O docente, ao pedir que dividam, esperava que cada um pegasse três parafusos, mas tal hipótese não foi confirmada, pelo fato de talvez as crianças não conseguirem operar tal lógica. Da mesma forma, para a Criança 12 ter mais equivalia a ter todos. Por meio da situação descrita, podese pensar que mesmo as crianças da turma terem a mesma idade, muitas vezes, as estruturas cognitivas encontram-se em diferentes estágios de desenvolvimento.

Além das atividades em que crianças desenvolveram habilidades de conservação do número, em outras ocasiões percebia-se que, nos momentos das brincadeiras infantis e das explorações dos materiais presentes, emergiam situações que oportunizavam o desenvolvimento do letramento matemático, isto é, compreender os usos sociais que a linguagem tem. Mesmo que essa habilidade não se desenvolva exclusivamente no contexto escolar, percebe-se que alguns recursos presentes no espaço da sala de aula favorecem esse processo. Um canto da sala de aula, por exemplo, foi transformado em Recanto de Leitura ou Biblioteca. Nesse 
pequeno espaço, disponibilizou-se um painel para colar imagens e uma estante, que além de livros e revistas, contém jornais. As crianças têm a possibilidade de manipular esses materiais em diferentes momentos do dia, tais como momentos de transição após o almoço, após concluírem suas atividades:

As Crianças 1 e 2 possuem pais que acompanham os jogos da equipe local
na Liga Nacional de Futsal, sendo que as conversas sobre o placar dos jogos
entre as crianças são comuns. Em um momento livre, a Criança 1 dirige-se
ao Recanto da Leitura e pega um jornal de circulação regional, ao folheá-
lo, depara-se com um logotipo da equipe que acompanham. Ele chama o
colega e o docente e comenta: "Está escrito aqui. Ninguém ganhou. Ontem
empatamos o jogo. Foi 1 a 1. Cada time fez um gol".

Na expressão da criança, percebe-se que ela carrega consigo e opera distintos conhecimentos matemáticos. O primeiro deles é o de reconhecer que, nesse caso, os números são empregados para identificar quem ganhou um jogo de futebol. Pode-se pensar ainda que o conhecimento da criança adquire um contexto mais complexo, pois ela percebe que ambas equipes marcaram a mesma quantidade de gols. Caso uma equipe tivesse vencido, ela precisaria colocar os números em uma ordem hierárquica, identificando o maior e o menor.

Nos excertos apresentados, percebe-se que os recursos disponíveis no espaço agem como mediadores das relações infantis. É por meio das dúvidas e das instigações que eles provocam que as crianças buscarão estabelecer relações com os seus pares, a fim de desenvolver uma maior compreensão do mundo e do meio que envolvem. Togneti $(2014$, p. 26) entende que a oferta de materiais de modo intencional pode permitir que às crianças "reinventar significados e possibilidades de uso, padrões e rituais de jogo originais e compartilhados com o pequeno grupo ou com toda a turma”. Kamii (2012, p. 44) corrobora com a afirmação anterior ao destacar que os adultos têm um papel crucial na organização dos materiais, de modo que encorajem o pensamento das crianças e possibilitem que elas estabeleçam diferentes relações entre os objetos que são manipulados.

\section{CONSIDERAÇÓES FINAIS}

No decorrer do estudo, buscou-se apresentar e analisar algumas situações que envolvem a interface entre aprendizagem lógico-matemática e o uso dos espaços e materiais na Educação Infantil. Para tanto, o espaço da sala de aula não foi pensado somente como um lugar no qual crianças e adultos conviviem e nem apenas como um cenário onde as crianças estabelecem relações com seus pares, mas sim como um ambiente provocador. Tornou-se perceptível que "um ambiente é um sistema vivo e mutante. Mais do que o espaço físico, ele inclui a forma como o tempo é estruturado e como se espera que os papeis sejam desempenhados" (RINALDI, 2016, p. 329). Nesse viés, pensa-se em um espaço que oportunize as aprendizagens lógico-matemáticas das crianças precisa estar assentado sobre um princípio de normalidade rica, isto é, desafiando as crianças a desenvolverem novas habilidades ou aprimorar aquelas que já possuem. 
Concorda-se assim com Moyles (2002, p. 71), quando afirma que a "[...] a sala de aula precisa ser vista como estando potencialmente cheia de problemas a serem resolvidos, dos mais simples aos mais amplos, e precisa oferecer uma estrutura estável a partir da qual as crianças possam explorar objetos, situações e eventos". Pensa-se que atualmente é incoerente pensar a Educação Infantil apenas sob uma perspectiva de cuidado. Torna-se fundamental existir uma intencionalidade pedagógica nos planejamentos destinados para a primeira infância. No momento que se pensa "o espaço como um sistema de oportunidades para experiências possíveis" (FORTUNATTI, 2014 p. 43), a ideia de planejamento não se restringe apenas à organização de situações de aprendizagem para e com as crianças, mas também refletir sobre os elementos arquitetônicos que compõem os espaços educacionais.

Por fim, destaca-se que, no contexto da Educação Infantil, os diferentes elementos arquitetônicos devem ser pensados, não somente em uma perspectiva estética, mas sobretudo como objetos que irão compor uma estrutura de aprendizagens que visa favorecer o desenvolvimento infantil. Frente a isso, entendese que os espaços e os materiais oferecidos às crianças, quando são pensados em uma perspectiva de desafio, podem favorecer o desenvolvimento de habilidades que antecedem a construção do número.

\section{REFERÊNCIAS}

ALARCÃO, I. Professores reflexivos em uma escola reflexiva. 6 ed. São Paulo: Cortez, 2008.

FORNEIRO, L. I. A Organização dos Espaços na Educação Infantil. In.: ZABALZA, M. A. Qualidade em Educação Infantil. Porto Alegre: Artmed, 1999. p. 229-281.

FORTUNATI, A. San Miniato e a Educação das Crianças: A história, os dados e os conceitos-chave, In.: FORTUNATI, A. A Abordagem de San Miniato para a

Educação das Crianças: Protagonismo das crianças, participação das famílias e responsabilidade da comunidade. Pisa/Itália: Edizioni ETS, 2014. p. 35-45.

GANDINI, L. Conectando-se por meio dos espaços de cuidado e de aprendizagem. In.: EDWARDS, C.; GANDINI, L.; FORMAN, G. (orgs.). As cem linguagens da criança: A Experiência de Reggio Emilia em transformação. v. 2. Porto Alegre: Penso, 2016. p. 315-336.

Glossário. In.: GANDINI, L. et al (orgs.). O papel do ateliê na Educação

Infantil: A inspiração de Reggio Emilia. Porto Alegre: Penso, 2012.

HORN, M. da G. S. Sabores, cores, sons, aromas: A organização do espaço na Educação Infantil. Porto Alegre: Artmed, 2004.

KAMII, C. A criança e o número. Campinas, SP: Editora Papirus, 2012.

MOYLES, J. R. Só brincar? O papel do brincar na educação infantil. Porto Alegre: Artmed Editora, 2002. 
PIAGET, J. Seis estudos de Psicologia. Rio de Janeiro: Editora Forense, 1977.

RINALDI, C. Diálogos com Reggio Emilia: Escutar, investigar e aprender. Rio de Janeiro: Paz e Terra, 2016.

TOGNETTI, G. Começando pelos bastidores: A complexa articulação da intencionalidade educativa. In.: FORTUNATI, A. A Abordagem de San Miniato para a Educação das Crianças: Protagonismo das crianças, participação das famílias e responsabilidade da comunidade. Pisa/Itália: Edizioni ETS, 2014. p. 25-34. 